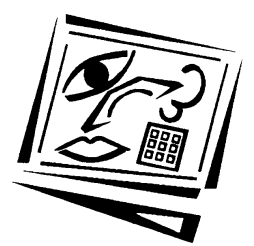

\title{
Organisational and technological skills: The overlooked dimension of research training
}

\author{
Renata Phelps, Kath Fisher and Allan Ellis \\ Southern Cross University
}

\begin{abstract}
Over the last three decades new technologies have emerged that have the capacity to considerably streamline the research and publication process and enhance the efficiency and effectiveness of research. This paper argues that to achieve high quality research training in the context of today's government and industry priorities, there must be a renewed focus on the organisational and technological skills that are appropriate to research. It reports on a survey of both researchers in training (higher degree research students) and early career researchers across a number of Australian institutions. The study revealed moderate levels of confidence in these areas but also found strong evidence that researchers see these aspects of research as very important and that they require greater knowledge, skills and support. The paper recommends inclusion of these organisational and technological aspects of research in research training programs and that higher education institutions take seriously the importance of such skills and do not assume that beginning researchers are already adequately trained in these skills.
\end{abstract}

\section{Introduction}

My lack of knowledge of the computer programmes I work with leads to time consuming glitches and frustration. However, if I take the time to learn these systems, I will be detracting from my real area of study. If I had known how important these skills were going to be, I would have taken a year out and gone to TAFE to get up to speed (survey respondent).

Twenty or thirty years ago, when many current $\mathrm{PhD}$ supervisors would have completed their own dissertations, a comment such as this would have been unheard of. To be sure, postgraduate researchers (and indeed all researchers) would have needed good organisational skills and systems in the past, but they would have been confined to aspects such as time management, library searching skills, management of paper files and efficient card systems. Most would not have needed even basic typing skills and would have been limited to literature available in a small number 
of accessible libraries. They would have laboured over bibliographies (or paid others to!) and unless working in computer science or a related field would probably have done only the most elementary computer analysis of their data.

The landscape of postgraduate research has altered dramatically in just a few decades. Astonishing advances in information and communication technologies are changing the way that research can be done by both postgraduate researchers and other professional and academic researchers. Three major developments have come together to put unprecedented power into the hands of the researcher: the Internet provides global connectivity; the personal computer provides processing power; and an increasing range of user friendly applications, often involving point and click web based interfaces, provide the information management and organisational tools, which can lead to real efficiencies in research processes.

In Australian universities, such advances in available technologies have combined with political imperatives for timely completions and 'industry ready' graduates (Kemp, 1999a, 1999b; Gordon \& Gallagher, 2000). The resultant funding frameworks that target completions place significant pressures on supervisors and institutions generally to increase support and training for postgraduate students as well as to find ways to ensure their students complete within specified time frames. At the time of writing (September 2005), Australian universities are having to contemplate the implications of the introduction of the 'Research Quality Framework' (based on the Research Assessment Exercise in the UK) which heralds further concentration of research into areas of excellence (Expert Advisory Group for an RQF, 2005). The implications for postgraduate research are still unclear, but there is no doubt that all researchers are being forced to improve the efficiency, quality and excellence of their research output. A number of less research intensive universities (including our own) face an uncertain future if they do not radically transform their research and research training practices.

As well as this changing context, there has been a significant and sustained growth in Australian higher degree research (HDR) student numbers (researchers in training) over the last two and a half decades, with numbers of $\mathrm{PhD}$ candidates, for example, rising from 9,298 in 1990 and 22,525 in 1996 to 37,685 in 2004 (DEST, 2005).

Table 1 shows age profile data for all enrolled HDR students (higher degree research students enrolled in both $\mathrm{PhD}$ and research Masters degrees) in 2004. Note that approximately two-thirds of enrolments are over 29 years of age, and close to $40 \%$ are over 40 . This distribution is almost identical for 
both Masters and PhD candidates. Because such a significant proportion of higher degree researchers are mature aged, they are not necessarily up to date with the latest relevant technological developments or organisational practices.

Table 1: 2004 higher degree research enrolments by age and gender (DEST, 2005)

\begin{tabular}{|c|c|c|c|c|c|}
\hline \multicolumn{2}{|c|}{} & \multicolumn{2}{c|}{ Doctorate by Research } & \multicolumn{2}{c|}{ Masters by Research } \\
\cline { 3 - 6 } \multicolumn{2}{c|}{} & Number & $\%$ & Number & $\%$ \\
\hline \multirow{3}{*}{$\begin{array}{c}\text { Age } \\
\text { range } \\
\text { (years) }\end{array}$} & 19 and under & 6 & 0.01 & 1 & 0.01 \\
\cline { 2 - 5 } & 20 to 24 & 4970 & 13.19 & 1404 & 14.59 \\
\cline { 2 - 5 } & 25 to 29 & 8632 & 22.90 & 2069 & 21.50 \\
\cline { 2 - 5 } & 30 to 39 & 10928 & 29.00 & 2795 & 29.04 \\
\cline { 2 - 5 } & 40 to 49 & 8075 & 21.43 & 2037 & 21.16 \\
\cline { 2 - 5 } & 50 to 59 & 4186 & 11.11 & 1068 & 11.10 \\
\cline { 2 - 5 } & Over 60 & 888 & 2.36 & 250 & 2.60 \\
\hline \multirow{4}{*}{ Gender } & Male & 19182 & 50.90 & 4738 & 49.23 \\
\cline { 2 - 6 } & Female & 18504 & 49.10 & 4886 & 50.77 \\
\hline Total & & 37686 & $79.66 \%$ & 9624 & $20.34 \%$ \\
\hline
\end{tabular}

Given this context, the imperative to support research students to work efficiently and produce excellent dissertations in the shortest possible time requires a rethinking of research training strategies. In this paper we argue that organisational and technological skills are critical aspects of research that are often overlooked and undervalued by supervisors and institutions. After discussing the scope of such skills and capabilities and how students are currently introduced to these aspects of research, we report on the results of a survey of Australian universities exploring how current postgraduate research students and new researchers view the organisational and technical aspects of their research.

\section{What are organisational and technological research skills?}

Throughout this paper we refer broadly to organisational and technical skills. Within this we encompass those foundational aspects of research practice associated with managing research which are non-discipline or topic specific, such as:

- time management skills, balancing conflicting demands and dealing with distractions;

- project management skills, including setting priorities, meeting deadlines or working with a team of researchers;

- idea management skills, such as effective note taking, summarising, using logbooks, journals and mindmapping; 
- information literacy, including effective and focused electronic literature searching skills as well as strategies for managing large amounts of information including use of bibliographic software (such as EndNote);

- organisation of physical workspaces, including sorting and filing;

- efficient and appropriate data collection and data analysis strategies whether with or without software;

- writing strategies, including use of advanced word processing features;

- presentation and dissemination skills, such as desktop publishing, hypertext, presentation software and the use of multimedia and electronic publication of theses;

- communication and networking strategies, such as email, wikis, blogs, web publishing, discussion lists and Internet telephony; and

- foundational information technology skills, such as the ability to install and update software (in particular antivirus software), manage files and backup procedures, move files across networks and understand elementary security issues.

\section{Training in technological aspects of research}

\section{The need for training}

As Table 1 indicates, many postgraduate students, particularly in the humanities, return to study as mature aged students, having been away from formal education for some time. Even those progressing from undergraduate study face considerable challenges adapting to the independence of postgraduate research, the need to organise and manage large quantities of literature and data, and the open ended scope and timeframe of research. For many of these students, advanced technologies that assist the research process have not been part of their undergraduate experience nor, in many cases, have they been part of their subsequent work experience. Expectations that they must adopt technological approaches to data collection and analysis, literature searching, thesis writing and so on can therefore be quite challenging for such students. While researchers inevitably do have to learn such skills through trial and error, their strategies are not necessarily efficient or effective. From our observations, even experienced researchers remain unaware of the potential for these technologies to assist in a wide range of research processes.

While it would be ideal for all postgraduate research students to have welldeveloped organisational and technical skills before enrolling, the reality is that many such skills need to be developed and refined during candidature. While there exist a range of 'survival guides' for postgraduate research students (such as Elphinstone \& Schweitzer, 1998; O'Leary 2004; Oliver, 2004), very few if any of these focus specifically on providing 
insights into recent technological and organisational developments that can assist the research process.

\section{The role of supervisors}

Traditionally, postgraduate research training has been provided solely within a student-supervisor relationship. However, the nature, content and breadth of learning that occurs through such relationships can vary significantly. Supervisors have rarely had any formal training or guidance in supervision, beyond the experience they had themselves as research students. Although some universities now require their supervisors to attend workshops, such training is by necessity limited in both scope and length. By and large, supervisors' style, methods and approaches have generally been developed from their own experiences (Pearson, 2002). The prevalence of the 'master-apprentice' model of postgraduate supervision (Frankland, 1999; Leder, 1995) can mean that 'the supervisor's research preferences and prejudices can constrain the scope, perspectives, methodology and directions of a student's work' (Leder, 1995, p.5).

While some supervisors do provide students with guidance and advice on organisational and technological aspects of research, our experience would suggest that many view these as skills, knowledge and abilities that students will just 'pick up' or should have already acquired during their undergraduate studies. Some consider it the student's responsibility to seek out and gain these skills. The comment at the head of this paper suggests this may be neither an unreliable assumption nor an unreasonable expectation! Our experience has shown that those established researchers who gained their research qualifications many years ago often have little experience with current technologies and applications that may benefit their students' research. Furthermore, such supervisors can be resistant or even antagonistic towards technology, which may disadvantage students who are undertaking their research in a more competitive and technologically dependent context.

\section{Preparatory courses}

Research students are usually required to have completed particular preparatory courses as a prerequisite for acceptance into postgraduate research programs; such research methods courses, however, usually focus on methodological, epistemological and theoretical aspects of research and specific research methods tend to be covered in a general and introductory way. These courses rarely focus on, or even consider, the more pragmatic management process or technological skills that support and drive the day to day research process. 
Some universities do offer short workshops covering some of the more 'evident' areas of need such as using bibliographic software, specific qualitative or quantitative data analysis software, or information seeking skills (for example see Banytis, 2003; Brooks \& Fyffe, 2004). However, as Parry and Hayden (1999) point out, providing opportunity for training is not always sufficient in itself because many postgraduate students, particularly in disciplines such as management or education, are already experienced professionals and are reluctant to seek advice or learn from their peers. Furthermore, because there is not usually a 'critical mass' of postgraduate research students requiring specific skills at the same time, training programs are frequently seen as not viable (Evans \& Pearson, 1999).

Often such training is provided in a purely technical fashion, without being informed by the 'everyday' practices of experienced researchers, thus failing to convey the real efficiencies that software can offer or the more pragmatic and organisational processes that can benefit researchers. Furthermore, consistent with recent research in other areas of computer education (Phelps \& Ellis, 2002a, 2002b; Phelps, Graham \& Kerr, 2004), technology is evolving at such a rapid rate, that if an individual undertakes traditional, directive style training in how to use a particular piece of software, the acquired knowledge is likely to be inadequate or out of date in a very short period of time. 'Just in time' learning can be far more effective, but researchers need to be aware of what technology is available, and where to seek help and support when it is required, as in many fields the 'don't know what you don't know' factor plays an influential role. Computer training thus presents significant challenges at both individual and organisational levels because a relevant computer education program requires more than mere skills training. It also involves changes in attitudes, values and beliefs and approaches to learning that support their continual adaptability to change (Phelps, in press 2006) and capability to keep exploring new technologies and processes.

\section{Method}

To investigate further the need for training and support in organisational and technological aspects of research in the Australian context, we conducted a web based survey of postgraduate students and researchers to gain a snapshot of their levels of confidence in relation to these dimensions of the research process as well as perceptions of their importance. The remainder of the paper reports on the findings of this research.

In July 2004 the Directors of Graduate Studies at Australia's universities and Institutes of Technology were approached and asked to distribute an email requesting participation in a survey of higher degree research 
students. The web based survey sought self reported details on the technical and organisational skills, systems and strategies used by new and developing researchers (enrolled higher degree students) and staff (recent higher degree graduates). It asked a total of 21 questions (both quantitative and qualitative). Nine of the 36 institutions approached agreed to participate in the survey and 252 surveys were returned. Response rates to individual questions were $95 \%$ or greater.

The nine participating universities, in order of number of respondents, were: James Cook (19.4\%); University of Technology, Sydney (19.4\%); Flinders (19.0\%); Southern Cross (9.9\%); Charles Darwin (9.5\%); University of Western Sydney (7.9\%); University of the Sunshine Coast $(6.3 \%)$; Monash (2.4\%); and Charles Sturt (1.6\%). Other/non-defined or not clearly defined institutions contributed $2.0 \%$ of responses, while a further 6 institutions (Australian Catholic University; University of Southern Queensland; University of Melbourne; University of Sydney; RMIT and Deakin University) were represented by one respondent $(0.4 \%)$ each, accessed through other networks.

The low response data rate from the 36 Australian institutions was somewhat disappointing, with neither emails nor follow up letters eliciting further response. One institution indicated that they were in the process of surveying their research students themselves and thus preferred not to participate. This experience appears to demonstrate:

- the difficulty of gaining access to and communicating with research students across Australian institutions (no single body or communication mechanism represents this group);

- an apparent lack of priority placed on understanding the needs of research students at an institutional level; and

- a lack of willingness by research administrators to see the benefits of this type of research.

While this relatively low response rate placed limitations on the study, the information obtained is nonetheless instructive, and offers valuable preliminary data in this area of research training. One further limitation should be noted. As a web based survey, promoted via email, only those researchers using these basic technologies would have been alerted to the study. Those who were not at all confident with technology and did not use email or the web, may not have had the opportunity to participate.

\section{Profile of respondents}

The following table summarises the main demographics and research characteristics of the survey respondents. 
Table 2: Profile of respondents $(\mathrm{n}=252)$

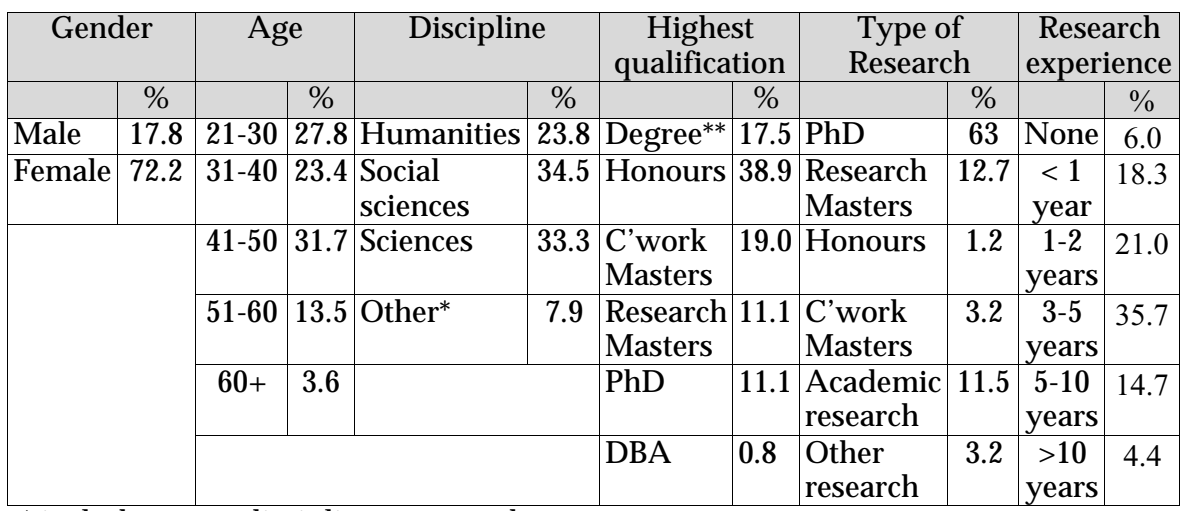

* includes cross-disciplinary research

**includes graduate certificate and graduate diploma

(Note that percentages do not total 100 due to missing responses)

In comparison with Table 1, the age cohorts are reasonably aligned with Australia wide data, but our survey is much more highly represented by women than the national cohort of research students, which has a much more even male/female split. While the levels of research experience were higher than expected from our targeted group of postgraduate and beginning researchers, this does lend greater significance to the findings of the research. It should also be kept in mind that a significant majority of participants come from the humanities and social sciences where there may be less access to software or specific technical training courses.

\section{How confident are researchers in their technical, organisational and project management skills?}

The survey asked eight questions to elicit respondents' assessment of their levels of skills, usage and confidence in a range of areas such as literature searching, note taking and summarising, filing, general use of computers, backing up, time management and peer group support. Table 3 displays their responses; cells scoring over $25 \%$ are shaded to aid identification.

Overall, respondents reported neutral to moderate levels of confidence. The activity that received the overall highest rating was 'Confidence in using computers to support research'. While the survey did indicate general confidence and moderate levels of skill, it was interesting that higher levels of confidence and skills were not reported on such essential research activities as literature searching, note taking and backing up given the overall level of experience of the sampled researchers. 
Table 3: Response rates to self assessment questions ( $\mathrm{n}=252)$

\begin{tabular}{|l|c|c|c|c|c|}
\hline \multirow{2}{*}{ Question } & \multicolumn{5}{|c|}{ Response rate (\%) } \\
\cline { 2 - 6 } & $\begin{array}{c}\text { Low } \\
1\end{array}$ & 2 & $\begin{array}{c}\text { Medi- } \\
\text { um 3 }\end{array}$ & 4 & $\begin{array}{c}\text { High } \\
5\end{array}$ \\
\hline $\begin{array}{l}\text { Confidence in current literature } \\
\text { searching skills }\end{array}$ & $1.2 \%$ & $14.6 \%$ & $37.9 \%$ & $36.8 \%$ & $8.7 \%$ \\
\hline $\begin{array}{l}\text { Level of organisation taking notes and } \\
\text { summarising literature }\end{array}$ & $4.0 \%$ & $22.1 \%$ & $44.7 \%$ & $26.5 \%$ & $2.0 \%$ \\
\hline $\begin{array}{l}\text { Level of feeling overwhelmed covering } \\
\text { the literature in research field }\end{array}$ & $1.2 \%$ & $10.7 \%$ & $25.3 \%$ & $49.4 \%$ & $12.6 \%$ \\
\hline $\begin{array}{l}\text { Level of organisation filing or archiving } \\
\text { literature }\end{array}$ & $4.3 \%$ & $25.7 \%$ & $37.9 \%$ & $23.3 \%$ & $7.9 \%$ \\
\hline $\begin{array}{l}\text { Confidence in using computers to } \\
\text { support research }\end{array}$ & $1.2 \%$ & $13.0 \%$ & $30.0 \%$ & $31.2 \%$ & $22.1 \%$ \\
\hline $\begin{array}{l}\text { Confidence in backing up electronic } \\
\text { research files }\end{array}$ & $5.5 \%$ & 15.8 & $26.1 \%$ & $31.6 \%$ & $19.8 \%$ \\
\hline $\begin{array}{l}\text { Frequency of use of peer support groups } \\
\text { or networks }\end{array}$ & $20.9 \%$ & $32.0 \%$ & $32.0 \%$ & $9.1 \%$ & $4.7 \%$ \\
\hline $\begin{array}{l}\text { Time management skills in relation to } \\
\text { research }\end{array}$ & $3.6 \%$ & $24.9 \%$ & $46.6 \%$ & $20.6 \%$ & $3.6 \%$ \\
\hline
\end{tabular}

(Note that percentages do not total 100 due to missing responses)

\section{What are researchers using computers to do?}

The survey posed a set of questions related to the type of software packages used by respondents. Table 4 summarises the responses received, presented in rank order based on level of use. Only three types of programs rated either very high (over 90\%) or high (over 75\%). Not surprisingly these were word processors, email and bibliographic software. However, given the universal nature of referencing in research writing and the need for accuracy in formatting references (one of the hallmarks of academic writing), it is notable that bibliographic software use was not rated closer to $100 \%$. For students at institutions without a licence, cost may be a factor here. Also, it is worth noting that the rating of more advanced word processing features was in the range $31 \%$ to $62 \%$, clearly indicating that the full potential of these programs in supporting research writing was far from being realised. This is an unexpected result given the critical importance of such programs and the efficiencies which can be gained from exploiting such advanced features when managing long documents such as a thesis.

While the usage levels of more specialised software packages such as graphics and digital video is likely to reflect the individual demands of different disciplines, it should be noted that more general purpose software that could assist with the organisation of a research project (such as mindmapping, flowchart, visual organising and project management 
packages) did not receive a significantly higher usage rating. The low usage rating of voice recognition and video conferencing (only $4 \%$ ) suggests that either the newest technologies have had little penetration into the research environment, or that researchers have not yet perceived their potential as research tools.

Table 4: Use of a range of technological applications $(n=252)$

\begin{tabular}{|l|c|c|l|c|c|}
\hline \multicolumn{1}{|c|}{ Application } & $\begin{array}{c}\text { Not } \\
\text { used } \\
\%\end{array}$ & $\begin{array}{c}\text { Used } \\
\%\end{array}$ & \multicolumn{1}{|c|}{ Application } & $\begin{array}{c}\text { Not } \\
\text { used \% }\end{array}$ & $\begin{array}{c}\text { Used } \\
\%\end{array}$ \\
\hline Word processors & 1.2 & 97.2 & $\begin{array}{l}\text { Qualitative data analysis } \\
\text { software }\end{array}$ & 75.4 & 16.3 \\
$\begin{array}{l}\text { Styles } \\
\text { Outlining } \\
\text { Track changes/editing } \\
\begin{array}{l}\text { Tables of contents } \\
\text { Linking documents }\end{array}\end{array}$ & 1.6 & 96.5 & & & \\
\hline Email & 62.3 & & & \\
\hline Bibliographic software & 20.6 & 75.8 & $\begin{array}{l}\text { Mindmapping/ flowcharts/ } \\
\text { visual organising } \\
\text { website) }\end{array}$ & 84.5 & 13.5 \\
\hline $\begin{array}{l}\text { Quantitative data } \\
\text { analysis software }\end{array}$ & 38.5 & 57.5 & $\begin{array}{l}\text { Project management } \\
\text { software }\end{array}$ & 84.5 & 13.5 \\
\hline $\begin{array}{l}\text { Mailing lists or } \\
\text { discussion groups }\end{array}$ & 44.4 & 54.4 & Survey software & 92.1 & 4.4 \\
\hline $\begin{array}{l}\text { Graphics or drawing } \\
\text { software }\end{array}$ & 48.0 & 48.8 & Voice recognition software & 92.1 & 4.4 \\
\hline $\begin{array}{l}\text { Digital video or } \\
\text { photographs }\end{array}$ & 62.7 & 33.7 & Video conferencing & 92.9 & 4.0 \\
\hline
\end{tabular}

(Note that percentages do not total 100 due to missing responses)

Respondents were also asked to indicate the type of Internet connectivity they had from home. The majority $(60 \%)$ had dialup connectivity, with $15.1 \%$ having higher speed ADSL and $7.9 \%$ cable connectivity. The relatively low level of home access by researchers to high speed Internet access may be reflective of the traditional limited financial resources of research students, and/or their preference for online access while on campus, as well as issues regarding access to high speed Internet infrastructure in rural areas. Of course, with rapid take up rates and reducing costs, these figures are unlikely to be reflective of current (2006) usage.

\section{What technological, organisational or management skills or knowledge are important for researchers?}

The survey also sought to collect qualitative data and asked beginning researchers two related questions: 
- What technological, organisational or management skills or knowledge do you feel you need to build or improve to support your research activities?

- What technological, organisational or management skills or knowledge do you think it is important for a new researcher to gain?

Responses to these questions were found to fall into eight broad themes, as follows:

1. management of time and motivation;

2. general organisational and computer skills;

3. personal organisation and management;

4. communication and networking;

5. dealing with literature;

6. data collection, management and analysis;

7. writing; and

8. publishing and disseminating.

We address each of these eight themes in turn. In exploring these themes we aim to present the broad diversity of ideas raised. We have provided only a general indication of the number of respondents mentioning the issue. As an open ended question this might range from $40+$ respondents to only one or two. Thus, while some suggestions were made by only a small number of respondents these ideas and suggestions, where they were sufficiently novel or divergent, are also included.

\section{Management of time and motivation}

Overwhelmingly, the most frequently mentioned issue which respondents felt they needed to develop or improve on was time management. Many commented that this was a major imperative for their own development. The ability to 'balance unpaid and paid hours of work' and to 'shut out the rest of my life to get on with my research' were indicative of identified needs. Skills of prioritisation, focus, writing constantly and avoidance of procrastination were seen as key for beginning researchers. As one respondent expressed 'it is often easy to get bogged down on tedious work, and to waste time avoiding doing work that needs to be done.' Another recommended, 'Just get in and do it... the sooner you start the sooner you finish!!' Having clearly defined objectives and adhering to these were noted as important, as was focusing on one thing at a time and 'doing rather than just talking about it!' The ability to subdivide large pieces of work into manageable subtasks and to set small daily goals was a critical strategy.

Related to issues of time management was management of motivation, particularly when working on tedious tasks or when research wasn't going as planned. The lack of imposed deadlines which characterise many 
research undertakings mean that researchers require 'self discipline to do something every week'. Several comments were made about the psychological impacts of the research process. As one respondent noted:

It is vital to learn how to cope with the inevitable depressive and isolating effects of this kind of research and to learn skills and techniques that will help you to persist and achieve in spite of the motivational chasms that you will encounter.

Important advice was to 'keep trying to think of the big picture and beyond all the work involved in producing a worthwhile and valid thesis'. There was an expressed recognition that time management was rarely 'taught' and that this would be valuable:

I tend to feel very guilty sometimes if I feel that I haven't done much work.

Nobody has really helped me how to manage my time effectively and I

would really like to get an insight into how to do this to overcome the

$\mathrm{bad} / \mathrm{sad}$ moods/depressed states.

One respondent also mentioned the importance of taking 'time out', away from research work.

\section{General organisational and computer skills}

A surprising number of respondents mentioned their overwhelming need for general computer or technical skills, and greater awareness of how computers can assist with research (including an understanding of what software is available). For others, the identified issue was how to use computers more efficiently or effectively than they already do, or to use the more 'advanced features of the computer'. Only one respondent mentioned that computer access was a problem, although another focused on the need for more reliable computers with secure data storage and reliable programs. Another referred to the benefits of becoming aware of the availability of tape recorders and transcribers.

While many respondents saw general computer skills as 'paramount' for beginning researchers, so too were general personal organisational skills. Respondents mentioned the need to improve their general filing skills, including 'proper filing of notes' or 'organisation of research materials into a regulated system'. One respondent saw filing systems as in 'desperate need' as 'lost files are my biggest time waster'. Another yearned for 'ways to categorise information continuously that are simple - I have developed fairly complex systems in the past'. Note taking was also identified by a number of respondents as areas of personal need. One experienced researcher recommended that new researchers should 'keep a detailed log book/diary. It's amazing how details which seem like overkill to note at the time, are important to jog your memory later!' Project management skills 
were identified as needed by a number of respondents, including specific mention of skills in managing large projects, or the use of project management software. Here we might also include issues related to financial management or applying for grants.

\section{Communication and networking}

Higher degree research can be incredibly depressing and draining, but this can be negated (in some degree) by a close community of researchers. Learning skills to overcome this aspect of the degree is as vital as learning to negotiate the more technological aspects that are required to succeed at this level.

A significant number of respondents mentioned personal issues relating to networking with other researchers (including peers, colleagues or 'experts') as an area in which they needed further skills. For some this related to 'knowing how to build networks of people', while one referred to needing 'more confidence to discuss my project with others both in my field and not in my field'. For another, the issue related to finding 'the times and places to meet other researchers and academics relevant to my work'. The importance of these skills was clearly emphasised in the following statement: It is important that all researchers be taught how to 'sell' their research. It is
not simply a matter of being able to conduct sound research - although this
is important - but in being able to prove to others that the outcome is
important.

The establishment of peer support groups for 'psychological (attitudinal) support' was mentioned as a desired approach by a number of researchers; 'It is important for new researchers to know that it's ok to be initially overwhelmed by research life and for them to be able to join a support network to help them learn about aspects of research'. Another indicated that:

The research support group I attend regularly ( 3 or 4 times a month) has been most important to my progress. Without these critical friends who know my project in as much detail as I myself, to constantly encourage, advise and provide mentorship, I would have given up long ago.

Technical aspects of communication and networking which were mentioned included skills in creating web sites and skills in joining mailing lists and discussion groups.

Another key aspect of the research process was what were referred to as 'supervisor management skills'. Some students indicated a need to better understand what a supervisor is meant to offer and where their responsibility ends. A number of respondents mentioned the need for 
better or increased supervision, but also identified the need for mediation and negotiation skills, and assertiveness training.

\section{Dealing with literature}

A major area of identified need for researchers related to dealing with literature. A large number of respondents referred to the use of bibliographic software (including mention of specific programs or the need to use programs more efficiently). As one seasoned researcher indicated 'it is essential to make sure that every item checked is recorded, so that the researcher does not consult material that has already been checked'. There was extremely strong support for postgraduate researchers using bibliographic software from the beginning of their research process. As one respondent expressed, 'a system of referencing, notating and collating information from day one saves heaps of time on day 1000'.

A second key area of need for a significant number of researchers related to more effective or more sophisticated use of online databases. Somewhat surprisingly only a very small number of respondents mentioned needing improved web searching skills. In our experience it seems that many quite experienced researchers are not aware of, and thus do not use, more advanced web searching strategies nor the more specialised searching tools available on the Web. We suspect that the low number of respondents mentioning this may reflect a general lack of awareness of strategies for refining searches.

Of equal, if not greater importance, however were the organisation, management and filing of literature, including organisation of electronic resources. As one respondent noted:

Literature reviewing is a skill which is really important, and is often not taught to students. While searching for literature on a database is not too hard, the actual reading and summarising of technical papers can often be difficult and daunting.

These thoughts were reinforced by another respondent: 'organising literature is so important as it's overlooked a lot especially by those (who are) older (and) who can do it so easily; it's overwhelming when you are new'. Others mentioned specific issues such as the 'ability to tell apart relevant from not relevant information' and 'setting realistic standards for reading, noting, synthesising the literature' and 'knowing when to stop collecting and reading'.

\section{Data collection, management and analysis}

Data organisation, storage and management of large amounts of data were mentioned by a range of respondents, some referring to the need to know 
more about specific software such as database programs, electronic survey software; management of tape transcription; better skills with video and camera use, and better training with scientific equipment. One respondent captured the importance of these research activities well in noting that:

\footnotetext{
So much time gets wasted in every department I have seen - it is not the technology but the organisation... knowledge of how to maintain and archive records and data - when using great amounts - and maintaining databases would be the most important area.
}

Data analysis was also frequently mentioned as an area of need, both in terms of general data analysis skills and specifically in relation to qualitative or quantitative analysis techniques, including the need for support with general statistical processes and understandings. Data analysis software was a major focus. One respondent mentioned that they would like to learn to use a specific qualitative program but that they were 'not sure if it is worth the time spent'. Another identified that it would be 'useful to understand ways others have categorised data'. While the need for skills in using quantitative data analysis software was also mentioned by quite a number of researchers, a small number of respondents argued against the need to know how to use the software themselves, when there was access to statisticians who either knew or fully supported the process.

\section{Writing}

Writing itself was an area that received considerable focus. This not only included writing skills such as 'better efficiency in writing short and concise' or 'the ability to focus a broad hunch into a sound academic argument earlier rather than later in the development of research' but also technical skills associated with writing. A number of respondents mentioned the need for better word processing or desktop publishing skills including the ability to manage long documents, and use styles or automatic tables of contents features (something which might be considered as an essential skill for beginning researchers). One respondent recommended that new researchers start with a thesis template. Interestingly, only one respondent mentioned the need for improved typing skills.

\section{Publishing and disseminating}

A small number of respondents mentioned their desire to develop further skills in using presentation software such as PowerPoint, with one commenting that they wanted to learn to use it 'in a non-linear way'. A greater number of respondents mentioned the need to learn to use drawing, graphic or flowchart software to 'present information to others 
more clearly and concisely'. A small number also mentioned an interest or need in learning to use mind mapping software.

\section{The influence of institutional context}

The data indicated that there was very little difference between researchers from the various institutions in relation to the organisational and technical skills and strategies surveyed in the research. However when respondents were asked 'what elements of your institutional context do you feel support or detract from your research activities?' there were clearly institutional issues that impacted. Not surprisingly, this question elicited a wide range of responses, from those who were highly positive and effusively pleased with their institution's research culture, to those who expressed quite bitter negative sentiments such as feeling that research students were at 'the end of the food chain' or that they were being told 'here is a desk, submit your thesis in 3 years'. Broadly speaking, issues related to:

- supervision, including lack of access and lack of expertise in technological areas;

- financial support, including the inadequacy of scholarships, the need to take on part time work to survive and that 'researchers are forced to limit their research to that which requires few resources';

- isolation, including being off campus or part time and the need for informal networking amongst peers;

- research culture, particularly the importance of a supportive and 'collegiate environment that encourages early and late career researchers to exchange perspectives on the research process as well as research results'; and

- the crisis in universities, producing a context in which 'supervisors have difficulty juggling teaching commitments and support for research' and, perhaps more seriously, the sentiments expressed in the following:

Virtually all Australian universities are in crisis management at the moment, where there is pressure on researchers to come up with short term solutions that will get the place out of trouble. This in turn distorts the nature of institutional research, and encourages people to look at the immediate rather than the ultimate outcome.

A number of points were raised which were more specific, however, to technical and organisational aspects of research. One of the main ones related to isolation and research culture. Several students commented on issues concerning lack of private office space in their institution. Many spoke of this as a major distraction which, while 'fun' was not very productive and could 'often lead to competitiveness and intimidation if the student is stuck'. Advantages were also recognised: 'While it can 
sometimes be distracting and drain time (via coffees etc), this loss is negligible in relation to the gain incurred by having a support network surrounding you through the day to day slog'. These comments were similarly reinforced by another student with the opposite predicament:

I am very privileged to have my own office... However, it also detracts in the sense that it can get very lonely and I forget to socialise with others... I wish that I had someone to work with, that I could talk to about the good and bad things about PhD research and teaching at university.

Respondents made very positive comments about the advantages of remote access to library databases and electronic document delivery, although a small number raised issues in relation to file formats and limited journal subscriptions.

Institutional provision of support and training also received mention and seemed to vary considerably. One respondent noted that 'there is virtually no support for computer training/ presentation skills etc. We have access to great equipment, but our individual research skill requirements are not supported by the institution', while another noted that 'staff training and development offers a range of useful courses however having the time to do them is a big problem!' Another commented that 'as I am a distance student the University sets out everything in detail. However it would be helpful to have software on hand that would encourage time management and research skills'. The general message presented here is well summarised in the following quote:

Organisational support is essential. Without it, all the mentoring in the world will not result in a sustained rhythm of scholarly productivity ie, a cycle of grants, research and publication.

\section{General findings}

I think management skills are so often overlooked as being unimportant, which is a shame.

Only a very small number of respondents indicated that there were no technological, organisational or management skills which they felt they currently needed. One person, for instance, responded 'Nothing at the moment as I have transferred business/management skills to my academic skills'. While another indicated that 'My research skills have been well covered, it's remembering to have a life away from it that's the problem'.

By far the majority of respondents indicated that students were in significant need of such 'methodical and meticulous approaches to research practice'. Several responded that they had not heard of many of the types 
of programs mentioned in the survey and that they just 'don't know what is available'. One respondent commented that 'after this survey I feel like $\left(I^{\prime} m\right)$ in the prehistory - I feel that I need all the help I can get'. Only one respondent seemed to make the point that technical and organisational aspects of research were not necessary for researchers to learn:

I feel that it is not necessary that the researcher has all of the skills him/herself. However, what they need to know is what skills, techniques and particularly technological support are required for the project and how to access those.

There was generally very strong support for the need for training and information about these aspects of research. Suggestions included the need for 'a practical workbook' or 'a subject that research students do on organisational learning and management before they start the research degree'. Another stated that 'I believe a longer course on technical aspects of research would give you an excellent kick start... because I am sure many of us feel "all at sea" especially in the beginning.'

\section{Conclusions: Developing research students as organisationally and technically strategic}

While this study has been limited in terms of its scope and institutional response rate, it has nonetheless been valuable in exposing the range of technical and organisational needs of beginning researchers. Given the unexpected high level of reported research experience of the respondents, on the whole it would seem that researchers are only moderately confident in relation to technical skills and organisational processes. Although they would appear to get by with what they know, there is evidence to suggest that they recognise the need for greater knowledge and support to improve the effectiveness and efficiency of their research. Organisational and technical skills appear to be an overlooked dimension of research training.

In the current Australian research context, universities, like never before, are being required to both prepare and support research students to ensure timely completions and industry ready graduates. We argue that attention to fostering more advanced and sophisticated technical and organisational research skills is one important means of achieving this. Institutions would be wise to heed the comments of one respondent that PhD candidates are learning how to do research and should not be expected to know how to do everything from the start. On the other hand, while there is no doubt that learning how to do research occurs in the process of actually doing it, success is on the whole still dependent on the student's timely understanding about what particular training they need at different stages of their research project. 
This study supports the need for universities to implement training programs or support structures which aim to develop technically and organisationally strategic research and which assist beginning researchers to overcome the 'don't know what I don't know' issue. Beginning researchers themselves recommended that such concerns might form a focus or component of preparatory research courses. While many universities are offering training and support in most aspects of research training, specific courses in how to manage and organise research are still the exception. ${ }^{1}$

Inevitably, such courses can only provide guidance and suggestions to researchers. As one researcher noted:

Research approaches can't be prescriptive. Diversity of research comes from diversity of approaches and the working through of the trials and tribulations of postgrad work and life is something that you need to do.

There is no easy way or best way people just have to figure it out for

themselves.

Yet supporting researchers to overcome the 'don't know what I don't know' issue would appear to be of critical importance if postgraduate students are to become effective and efficient researchers, particularly in light of the current pressures on universities to improve their research performance. Furthermore, this research would suggest a need for enhanced communication and support mechanisms among postgraduate students themselves.

\section{Acknowledgements}

The authors would like to thank members of the ASCILITE community who supported this study, both by participating in the survey, and also volunteering to form case studies for the forthcoming book.

\section{References}

Banytis, F. (2003). The research higher degree student professional development program at Flinders University. In Partners in Learning. Proceedings of the 12th Annual Teaching Learning Forum, 11-12 Feb. Perth: Edith Cowan University. http://www.ecu.edu.au/conferences/tlf/2003/pub/pdf/08_Banytis_Fran.pdf

\footnotetext{
${ }^{1}$ One such course currently offered at Southern Cross University is a Graduate Certificate in Research Management that incorporates training in technological and organisational aspects of research. Drawing on the findings of this study, the authors have written a book addressing such themes, which will be published by Sage (London) later in 2006.
} 
Brooks, C. \& Fyffe, J. (2004). Are we comfortable yet? Developing a community of practice with PhD students at the University of Melbourne. In R. Atkinson, C. McBeath, D. Jonas-Dwyer \& R. Phillips (Eds), Beyond the Comfort Zone. Proceedings of the 21st ASCILITE Conference (pp. 163-169). Perth, 5-8 Dec. http://www.ascilite.org.au/conferences/perth04/procs/brooks.html

Department of Education, Science and Training (DEST) (2005). Selected Higher Education Statistics.

http://www.dest.gov.au/sectors/higher_education/publications_resources/pr ofiles/students_2004_selected_higher_education_statistics.htm

Elphinstone, L. \& Schweitzer, R. (1998). How to get a research degree: A survival guide. Sydney: Allen and Unwin.

Evans, T., \& Pearson, M. (1999). Off-campus doctoral research and study in Australia: Emerging issues and practices. In A. Holbrook \& S. Johnston (Eds), Supervision of postgraduate research in education (pp. 185-206). Coldstream, Vic: Australian Association for Research in Education.

Expert Advisory Group for an RQF (2005). Research quality framework: Assessing the quality and impact of research in Australia. Canberra: Commonwealth of Australia. http://www.dest.gov.au/sectors/research_sector/policies_issues_reviews/key _issues/research_quality_framework/issues_paper.htm

Frankland, M. (1999). The master/apprentice model for the supervision of postgraduate research and a new policy for research education. Australian Universities Review, 42 (1), 8-11.

Gordon, J. \& Gallagher, M. (2000). The challenges facing higher education research training. Paper presented at Quality in Postgraduate Education: Making Ends Meet, Adelaide.

Kemp, D. A. (1999). Knowledge and innovation: A policy statement on research and research training. Canberra: AGPS.

Kemp, D. A. (1999). New knowledge, new opportunities: A discussion paper on higher education research and training. Canberra: AGPS.

Leder, G. (1995). Higher degree research supervision: A question of balance. Australian Universities Review, 38 (2), 5-8.

O'Leary, Z. (2004). The essential guide to doing research. London: Sage.

Oliver, P. (2004). Writing your thesis. London: Sage.

Parry, S. \& Hayden, M. (1999). Experiences of supervisors in facilitating the induction of research higher degree students to fields of education. In A. Holbrook \& S. Johnston (Eds), Supervision of postgraduate research in education (pp. 35-53). Coldstream, Vic: Australian Association for Research in Education. 
Pearson, M. (2002). Research training and supervision development. Studies in Higher Education, 27(2), 135-150.

Phelps, R. \& Ellis, A. (2002). Helping students to help themselves: Case studies from a metacognitive approach to computer learning and teaching. Paper presented at the International Conference on Computers in Education (ICCE 2002), Auckland, New Zealand, 3-6 December. [verified 9 May 2006]

http://csdl.computer.org/comp/proceedings/icce/2002/1509/00/15091035.pdf

Phelps, R. \& Ellis, A. (2002). A metacognitive approach to computer education for teachers: Combining theory and practice for computer capability. Paper presented at Linking Learners: Australian Computers in Education Conference (ACEC2002), Hobart, Tasmania. http:/ /www.pa.ash.org.au/acec2002/ uploads/documents/store/conferences/conf_117_086_phelps.pdf

Phelps, R., Graham, A. \& Kerr, B. (2004). Teachers and ICT: Exploring a metacognitive approach to professional development. Australasian Journal of Educational Technology, 20(1), 49-68.

http:/ / www.ascilite.org.au/ajet/ajet20/phelps.html

Phelps, R. (in press 2006). The metacognitive approach to computer education: Making explicit the learning journey. AACE Journal (International Forum on Information Technology in Education). http:/ / www.aace.org/pubs/aacej/

Renata Phelps, Lecturer, School of Education

Southern Cross University

PO Box 157, Lismore NSW, Australia 2480

Email: renata.phelps@scu.edu.au

Kath Fisher, Postgraduate Support, Graduate Research College

Southern Cross University

PO Box 157, Lismore NSW, Australia 2480

Email: kath.fisher@scu.edu.au

Allan Ellis, Associate Professor, School of Social Science

Southern Cross University

PO Box 157, Lismore NSW, Australia 2480

Email: allan.ellis@scu.edu.au 